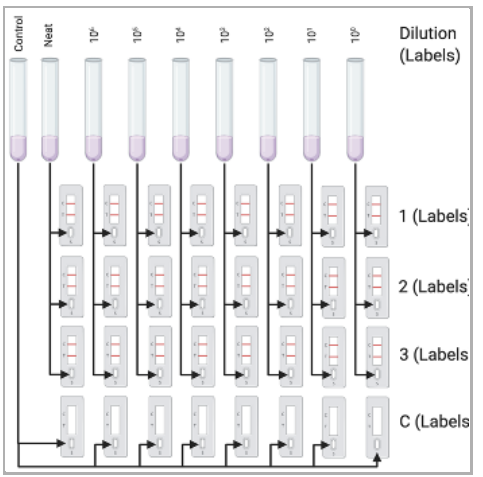

SEP 08, 2020

\section{open ठaccess}

DOI:

dx.doi.org/10.17504/protocol s.io.bk3jkykn

\section{External link:}

https://assure19.com

Protocol Citation: proposals, Dexter Poon 2020. Oceanit Lateral Flow Assay (LFA) Protocol. protocols.io https://dx.doi.org/10.17504/p rotocols.io.bk3jkykn

License: This is an open access protocol distributed under the terms of the Creative Commons Attribution License, which permits unrestricted use, distribution, and reproduction in any medium, provided the original author and source are credited

\section{Protocol status: In} development We are still developing and optimizing this protocol

Created: Sep 08, 2020

Last Modified: Sep 08, 2020

PROTOCOL integer ID: 41803

\section{(3) Oceanit Lateral Flow Assay (LFA) Protocol}

proposals $^{1}$, Dexter Poon ${ }^{1}$

${ }^{1}$ Oceanit Laboratories, Inc.

Dexter Poon: XPrize submission<smiles>C1CCCCCC1</smiles>

proposals

\section{ABSTRACT}

This experiment uses infectious WA1 strain of SARS-CoV2 and is conducted in a qualified BSL3 facility at the University of Hawaii John A Burns School of Medicine (Honolulu, Hawaii).

\section{MATERIALS}

\section{MATERIALS}

88 RNase A (10 mg/mL) Thermo Fisher Scientific Catalog \#EN0531

88 Triton X-100 VWR Scientific Catalog \#9002-93-1

88 BSA Sigma Aldrich Catalog \#A2153

88 Gold Nanospheres - Bare (Citrate) 80nm Nanocomposix Catalog \# AUCN80

88 TBSTween Sigma Aldrich Catalog \#9039-10PAK

88 Sample Pad Cytiva Catalog \#8134-2250

\title{
Oceanit Lateral Flow Assay (LFA) Protocol
}


This experiment use infectious WA1 strain of SARS-CoV2 and is conducted in a qualified BSL3 facility at the University of Hawaii John A Burns School of Medicine (Honolulu, Hawaii).

2 Aliquot diluent solution into centrifuge tubes

Diluent solution is cell growth media supplemented with $10 \%$ FBS.

3 Prepare lysis buffer with LFA capture molecule

Lysis buffer containing LFA capture molecule is Oceanit's proprietary formulation.

$4 \quad$ Virus stock $(4 \times 10 \mathrm{e} 7 \mathrm{pfu} / \mathrm{mL})$

Virus stock 10-fold serial dilutions.

$5 \quad$ 10-fold serial dilutions and control tubes

a.Tube $1-$ Neat $(4 \mathrm{e} 7 \mathrm{pfu} / \mathrm{mL})$; pfu = plaque forming units

b. Tube $2-10 \mathrm{e}-1$

c. Tube $3-10 \mathrm{e}-2$

d. Tube $4-10 \mathrm{e}-3$

e.Tube $5-10 \mathrm{e}-4$

f. Tube $6-10 \mathrm{e}-5$

g.Tube $7-10 \mathrm{e}-6$

h. Tube $8-10 \mathrm{e}-7$

i.Control - no virus

$6 \quad$ Add lysis buffer to dilutions

Add prepared lysis buffer to labeled individual LFA cassettes. Test and control lines are Oceanit's proprietary molecules.

$7 \quad$ Incubate 5 minutes 
$8 \quad$ Add to labeled individual LFA cassettes.

Add $250 \mathrm{uL}$ of the corresponding sample to individual LFA cassettes.

9 Record results with photography:
A.Amount:
B.Concentration: Virus stock and dilution range from $4 \times 10 \mathrm{e} 7 \mathrm{pfu} / \mathrm{mL}$ to 0 virus added.
C.Temperature: Virus stocks are stored at -80C; assay is performed at room temperature.
D.Duration of the experiment: 1 hour elapsed time.
E.Equipment: BSL3 containment, Class II biological safety cabinet, autoclave, pipette and disposable tips, disposable tubes, dedicated camera.
F.Reagents: Vero E6 cell culture growth media supplemented with $10 \% \mathrm{FBS}$, Oceanit lysis buffer + capture molecule (proprietary), LFA embedded test and control line molecules (proprietary) 